\title{
An Assessment of Work Life Balance Practice of Church Leaders: The Case Study of the Ethiopian Evangelical Church Mekane Yesus (EECMY)
}

\author{
Okello Oluch Wudo ${ }^{1}$ Abeba Beyene Mengistu $(\mathrm{PhD})^{2}$ \\ 1.The Ethiopian Graduate School of Theology, Addis Ababa, Ethiopia \\ 2.Addis Ababa University School of Commerce, Addis Ababa, Ethiopia
}

\begin{abstract}
This study assessed the work-life balance practice of church leaders in the case of the Ethiopian Evangelical Church Mekane Yesus (EECMY). Besides, it also evaluated the relationship between work to life conflict, life to work conflict, perceived organizational support, and perceived social support and work life balance. Quantitative research was employed to collect the primary data for the study. The study found that church leaders have low work life balance. Moreover, it discovered that work to life conflict and life to work conflict have strongly negative relationship with work-life balance of the leaders. Again, it also revealed that perceived organizational support and perceived social support have no significant relationship with work life balance. Hence, the study concluded that work to life conflict highly contribute to improper work-life balance of the church leaders than life to work conflict. Hence, the church (EECMY) must initiate work-life balance policies, strategies and familysupportive environments or culture and different mechanisms that are fundamental in enhancing work life balance of the leaders. Besides, church leaders should advocate for family-friendly benefits and supportive culture in the organization, utilize such benefits, fairly allocate and manage their times, and have supportive family members and friends.
\end{abstract}

Keyworks: Work Life Balance, Work to life Conflict, Life to Work Conflict, Perceived Organizational Support, Perceived Social Support.

DOI: $10.7176 / \mathrm{EJBM} / 12-4-06$

Publication date: February $29^{\text {th }} 2020$

\section{Introduction}

Both work and life are very important parts of employees' existence as work and life domains impact one another (Kebriaei et.al, 2016). Any good or bad thing that happens in personal life may positively or negatively affect the work of that individual. The roles that a person plays in a workplace may be incompatible with the roles he or she plays in a non-work domain. Hence, maintaining the balance between work and life, family and other obligations is a necessity and also a daunting task for employees and organizations. Good or poor work-life balance may respectively improve or deter the effectiveness and efficiency of both the employees and organizations.

Employees should balance their work and life. According to Hill and associates (2001) work-life balance is "the degree to which an individual is able to simultaneously balance the temporal, emotional and behavioral demands of both paid work and family responsibilities." The term "work-life balance" was brought into existence in 1986 in America with the concept of minimizing the intrusion that exists between work, life, and family obligations (Singh, 2014).

According to Lockwood (2003), in the 1980s and 1990s, companies had started using programs which mainly focused on supporting women with children. But prior to this, some companies were applying specific work-life programs by lowering employees daily working hours shift from eight to six which had enhanced employees' motivation and performance. However, as this same author stated, work-life balance became a research agenda and get attention from organizations when Kanter discussed it in 1977 in his seminal book entitled 'Work and family in the United States: A critical review and agenda for research and policy.'

Work-life balance is culture and context-oriented and people understand and express it in different ways(Lockwood, 2003). For instance, work-life balance can mean the problem of keeping the balance between work and personal life obligations for employees (De Cieri et.al, 2005), and to employers it can mean the way of providing supportive mechanisms so that effectively and efficiently perform their jobs with less concern about personal lives while at workplaces (Lockwood, 2003). As a result, many scholars have termed it differently such as 'work-life coordination', 'work-life interference'(Kumar \& Janakiram, 2017), 'work-family conflict', 'work or family balance'(Singh, 2014), and so on. Moreover, while the term work/family balance had been widely used, balance replaced it in order to incorporate the wide range of activities outside work such as sport and exercise, church, study, volunteer work, hobbies and etc.( Hudson Resource Development, 2005).

Though the main focus of work-life balance programs was for assisting women with children, currently it has included both women and men and the concept has expanded to other areas of responsibilities. Moreover, the 
issue of work-life balance has become an agenda as work and life domains are two important aspects for employees irrespective of their spheres( Hudson Resource Development, 2005). Hence, workforces around the world including those in the church want to enjoy and maintain a balanced work and personal lives.

Balancing work and non-work roles increases employees' efficiency and effectiveness, reduces their absenteeism and turnover; lessens stress, mental and physical health problems, enhances job satisfaction and performance (Saleem \& Abbasi, 2015), increases organizational performance, reputation and public images and so on(Sangarry \& Srinivasan, 2016). However, improper balance of work and life has detrimental effects on employees and organizations. Hence, this research examines the work-life balance practice of the leaders of the Ethiopian Evangelical Church Mekane Yesus.

\subsection{The Ethiopian Evangelical Church Mekane Yesus (EECMY)}

Being the second largest evangelical church in Ethiopia and the largest Lutheran Church in Africa, the Ethiopian Evangelical Church Mekane Yesus was established in January 21,1959. (Constitution of the EECMY: the fifth revised, 2004). This church desires to "see spiritually vibrant, resource-wide sustainable, and missionally passionate church" and with the motto "serving the whole person', also known as "holistic ministry" which means serving both the spiritual and material/physical needs of all human beings (Terfassa, 2017). Structurally Organized into central office, synods, parishes/presbyteries, congregations and preaching places(Constitution of the EECMY: the fifth revised, 2004), the church has over 8.7 million estimated total members (The EEECMY Statistics for 2017, 2018) and more than 7000 employees across the country (The EECMY Pension Commission statistics for 2018, 2018).

\subsection{Statement of the Problem}

Today's working environment including that of the church is very complex impacted by global competition, extreme pressure, persistent deadlines and increased use of technology(Darcy \& McCarthy, 2007). To be successful organizations need skilled workers who can perform multiple and challenging tasks such as handling crises, and work for long hours sacrificing times needed for other non-work roles(Muna \& Mansour, 2009).

The church environment in Ethiopia has become very competitive as the religious freedom granted in the constitution(The Ethiopian Peoples' Federal Democratic Republic Constitution, 1995) has brought growth and expansion to churches and the introduction of new emerging churches. Besides, the dynamic work environment and provision of quality services to stakeholders forced the EECMY to organize and introduce new initiatives like women department, stewardship and church economy department, diaspora ministry, five years strategic planning, and so on.

But effective implementation of such activities needs qualified and devoted leaders who must work for long hours and highly involve in complicated job. Indeed, the EECMY leaders are observed conducting meetings even on weekends, have frequent travels, and busy on phones discussing work related matters while at homes. Such tasks critically challenge leaders' capability to balance their work and life roles(Muna \& Mansour, 2009).

According to Hudson Resource Development (2005) better work-life balance leads to reduction in employees turnover and absenteeism, improvement of performance, job satisfaction, employees' retention and citizenship, better mental and physical health and so on. But, according to Muna and Mansour (2009), imbalanced work and life results in stress, poor quality of life, instability in marriage and family relations, poor mental and physical health and so forth.

Being among the church leaders under the EECMY, the researcher's personal experience and observation indicate that church leaders are suffering from health problems such as blood pressure, diabetes and so on. The researcher personally has experienced physical health problems (kidney problem) which most likely due to improper work-life balance. Again, church leaders are heard complaining about lack of enough time for other roles, inadequate family-friendly mechanisms, and low salary; hence the has faced frequent workforce turnover. Also, church leaders' families are heard complaining about lack of enough time given by their spouses.

Hence, assessing work-life balance practice of the church leaders provides the church with ample and appropriate information that can assist in revisiting its situation and human resources polices. According to May and Reynolds (2017), studies on religion and work-life matters are still limited. To the researcher's best knowledge, research has hardly been conducted on work-life balance of church leaders as many work-life balance related studies in Ethiopia focus on publics and private sectors like banks. Thus, this paper investigates work-life balance practice of the leaders of the Ethiopian Evangelical Church Mekane Yesus.

\subsection{Objective of the Study}

This study assesses the work-life balance practice of the church leaders in the case of the EECMY by surveying the relationship and impact of work-life conflict, life-work conflict, perceived organizational and social supports on work life balance. 


\section{Literatures and Hypotheses Development}

\subsection{The Concept of Work-Life Balance(WLB)}

The term work-life balance was brought into existence in 1986 in the United States (Meenakshi et.al.,2013). However, before that different initiatives had taken places, for instance, employees' and trade unions' demand for minimization of factories' long working hours in $19^{\text {th }}$ century (Hogarth \& Bosworth, 2009) and ratification of the Fair Labor Standards Act in 1938 by the American government that brought the reduction of the per week working hours to 44 hours (Syed, 2015). Since 1986, particularly in 1980s and 1990s, many companies started introducing and implementing work-life balance programs which primarily focused on support of women with children but later work-life initiatives have been widely inclusive of all employees regardless of gender (Lockwood, 2003).

Change in demographics, women participation in work, increase in number of dual career families, rapid change in working environment and technological advancement (Bulger and Fisher, 2012) have increased the importance of work-life balance for employees and employers(Saleem \& Abbasi, 2015). Thus, as per Pichler (2009) work-life balance has gained the attention of many people, institutions and scholars, and has become a widely employed term.

However, scholars have common definition of work-life balance and some do not use this term(Kalliath and Brough, 2008; Meenakshi et.al, 2013) because work-life balance is cultural and context-oriented and the term 'balance' conveys different meaning to different people(Viswanathan, \& Jeyakumaran, 2013; Bulger and Fisher 2012). Moreover, many working definition of the words 'balance', 'work' and 'life' have created such problem (Guest, 2002). To this author, 'work' means any activity that brings earnings for employees; whereas 'personal life' or 'family' denotes any non-work roles which may include but not limited to family, friendships, community involvement, spirit, leisure time, health and personal development activities (Guest, 2002).

Work life balance was considered to be 'unidirectional', but now scholars have recognized its bidirectional occurrences: work to family/life conflict and family/life to work conflict (Darcy \& McCarthy, 2007). Recently 'work-life balance' is preferred over 'work-family balance' to include wide range of activities such as family, study, sport/exercise, church related activities and so forth and for "legitimizing non-standard work arrangements for a diverse range of employees."(Hudson Resource Development, 2005). Hence, work-life balance mainly contains time-balance: the amount of time that a person devotes on work and life related obligations, involvement balance: the magnitude of psychological engagement in or dedicated to work and nonwork activities, and satisfaction balance: the contentment degree that the individual gain in work and non-work roles. But, recall that, as Meenakshi and his partners (2013) stated, work-life balance does not mean having equal balance since there is no uniformity and standardized balance among individuals daily and over time due to priorities differences.

Balanced work and life roles create better health and wellness for employees, improves organizational commitment and job satisfaction, productivity and performance, enables employees better achieve goals, creates family and marital stability, and so forth (Rao and Indla 2010). It can also lead to employees' problem of health and well-beings such as poor mental and physical health, high level stress, emotional exhaustion, poor appetite and fatigue and so on ( European Agency for Safety and Health at Work, E-facts sheet, 57).

\subsection{Theories of Work-life balance}

Work-life balance is founded on various theories such as spillover theory, border and boundary theory, and role conflict theory (Pradhan, 2016). According to AlHazemi and Ali (2016), spillover theory focuses on the relationship between work and life domains and states that employees take things such as emotions, attitudes, skills and behaviors experienced at work (life) into life or work and happens in two forms: positive and negative spillover. Positive spillover occurs when good things happen in one domain such as work initiates good impressions or motivation in another domain, life for instance, whereas negative Spillover happens when unpleasant things like depression in one domain (work or life) carry the same feeling or effect into another domain (life or work).

Besides, Border and Boundary theory according to Clark (2000) takes work and life as two separate spheres with borders and different commitments and objectives, ideologies, values and rules but that impact one another. As a result, in order for individuals to realize the desired balance they have to manage and negotiate between work and life domains, and their borders by creating the bridges. As per this same author, borders take three forms (physical, temporal and psychological borders) in the context of work and life domains; and "crossing borders' of work and life domains results in integration, smooth transitions and/or conflict which depends on the flexibility and permeability of the borders. More flexibility and permeability at borders of work and life domains bring integration, and easy transitions that likely accompanied by more conflict. But non-flexible and nonpermeable borders lessen integration and tighten transitions but reduce conflict.

Again, according to Biddle (1986), role conflict is "the concurrent appearance of two or more incompatible expectations for the behavior of a person." As per him, role conflict can happen (1) when a person has 
inadequate or incomplete expectations about roles, (2) when roles do not match one another, (3) when it is an obligation for an individual to perform a sequence of roles that do not fit together, (4) when a person has very many expectations. So, as per conflict theory concept the role demands in one domain make difficulty in accomplishing the role demands in another domain.

\subsubsection{Work to life conflict (WLC) and Work-life balance(WLB)}

According to Greenhaus and Allen (2011), work life conflict happens when participation in one role makes in hard to take care of or involve in another role. Hence, work-family conflict occurs in three forms which are timebased conflict, strain-based conflict, and behavior-based conflict ( Greenhaus and Bautell 1985).

Literatures have claimed a negative correlation between work to life conflict and work-life balance. Rincy and Panchanatham (2010) while developing a psychometric instrument to measure work-life balance concluded that work life conflict has significantly negative association with work-life balance. Besides, Banu and Duraipandian ( 2014) when trying to develop instruments that measure work life balance of Information Technology (IT) professionals in Chennai affirmed the negative relationship between work to life conflict and work-life balance. Nevertheless, Tasdelen-Karckay and Bakalim (2017) studied the mediating effect of work life balance on the relationship of work to life conflict, life to work conflict and job satisfaction, and founded that the conflict from work to life has negative relationship with and effects on the work-life balance of employees in Turkey. Thus, based on theoretical frameworks it can be hypothesized that work life conflict inversely relates with work life balance.

H1: Work-life conflict inversely relates with work life balance.

\subsubsection{Life to work conflict(LWC) and Work life balance(WLB)}

Life-work conflict occurs according to Darcy and McCarthy(2007) when life related tasks, requirements, expectations, commitments become incompatible with work-related responsibilities, that is, involvement in family or other life related activities make it hard for an individual to engage in work related activities; and such conflict happens in three aspects: time based conflict, strain based conflict and behavior based conflict(Carson et.al.,2000).

Researchers have shown an inverse relationship between and effect of life to work conflict and worklife balance. Rincy and Panchanatham (2010) while developing scales to measure work-life balance confirmed a negative interference and effect of personal life on work-life balance. Like manner, in developing scales to measure work life balance of IT professionals, Banu and Duraipandian (2014) stressed that personal life involvement in work spheres negatively relate to and affects employees' work life balance. Nonetheless, Tasdelen-Karckay and Bakalim (2017) studied the relationship between work-life conflict and job satisfaction by considering the effect of work-life balance, concluded that conflict that transmit to work from life has negative relation with and effect on work-life balance. So, it can be hypothesized that life-work conflict has negative relationship with work-life balance.

H2: Life-work conflict has negative correlation with work-life balance

\subsubsection{Perceived Organizational Support(POS) and Work-Life Balance (WLB)}

Perceived Organizational Support (also known as perceived workplace support) is the level of employees' perception about how their organizations or employers give appropriate value, recognition, appreciation towards their efforts and contributions and provide needed supports and cares concerning their well being(Eisenberger et.al.,1986). These include any support from organizations, supervisors or managers and co-workers to employees such as emotional support, instrumental support, information support and so on (Russo et.al., 2015).

Various researchers found a positive relationship between perceived organizational support and work-life balance. According to McCarthy and his partners (2013) the more employees perceive supports and care for well-being from their organizations, the more likely they exert balanced work and life responsibilities. Further, Yahya and Yap (2014) studied the relationship between workplace social support and work life balance and concluded that perceived organizational support has positive relation with work life balance; and an increase in perceived organizational support leads to increase in work-life balance. Likewise, Thakur and Kumar (2015) surveyed the effect of perceived organizational support and other factors on work-life balance and found that perceived organizational support has positive relationship with work-life balance and the former appeared to be a significant predictor of work-life balance. For the above theoretical structures it can be hypothesized that perceived organizational support positively correlates with work-life balance.

H3: Perceived Organizational Support has positive relationship with work-life balance

\subsubsection{Perceived Social Support (PSS) and Work Life Balance(WLB)}

Though some scholars treat it in a wider sense (Kaya et.al, 2012), perceived social support refers to the degree to which individual employees perceived how their family members, parents, relatives, friends support and care for their well beings and vice versa (Russo et.al., 2015). Social support includes instrumental support, emotional support, informational support, and appraisal support (Onyebuchukwu et.al., 2015).

Scholars who have studied the association between social support and work-life balance, for instance, Malik and his associates (2010) concluded that social support has positive influence on work-life balance. Moreover, a 
studied on the association of social support at both work and home with job satisfaction by taking work life balance as mediator found that partner support or perceived social support has positive relation with work life balance and plays a significant role in balancing work and life than co-worker support (Ferguson et.al., 2012). Likewise, Zhang and partners (2018) conducted a study on the relationship between social support, work-life balance and job satisfaction among middle and top level managers in China and concluded that social support has direct relationship with and more importantly enables individuals have work-life balance because it provides physical, emotional and informational resources to work domain. Hence, based on the theoretical frames the research hypothesize that perceived social support positively relate with work life balance.

H4: Perceived Social Support has positive relationship with work-life balance.

\subsection{Conceptual Framework}

This study has four independent variables and one dependent variables. Work-life conflict, life-work conflict, perceived organizational support, and perceived social support are independent variables; and work-life balance is the only dependent variable.

Figure 2.3: Conceptual Framework

\begin{tabular}{|l|l|}
\hline $\begin{array}{l}\text { Work-life Conflict } \\
\text { (WLC) }\end{array}$ \\
\hline \begin{tabular}{l|l|}
\hline \multicolumn{2}{|l|}{ Life Work Conflict } \\
(LWC)
\end{tabular} \\
\hline \begin{tabular}{l|l|}
\hline Perceived organizational \\
Support (POS)
\end{tabular} \\
\hline $\begin{array}{l}\text { Perceived Social Support } \\
\text { (PSS) }\end{array}$ \\
\hline
\end{tabular}

Source: The researcher

\section{Methodology}

3.1 Research Design

This paper employed quantitative method especially survey research design to measure the relationship between research variables and assess the impact of independent variables on dependent variable( Creswell 2013).

\subsection{Population and Sampling}

The population of the study consisted of church leaders of the EECMY at central office, synods/area works and joint programs located in regions and towns throughout the country. These include the presidents, vice presidents, treasurers and heads of departments and joint programs. This study employed stratified sampling method since the work of the church leaders in the church structure have homogeneity.

\subsection{Instrumentation}

This study collected primary data using self-administered questionnaires. Work to life/family conflict and life/family to work conflict were measured using 18 items questionnaires designed by Carlson, Kacmar and Williams (2000); and perceived organizational support was measured by 6 items from Eisenberger and associates (Eisenberger et al., 1986). All questionnaires were measured on five-points Likert scales ranged from strongly disagree (1) to strongly agree (5). Further, perceived social support was measured using 8 items developed by Vinkur and Van Ryn (1993). The items were arranged on five points Likert scales ranged from not at all (never) to a great deal numbered 1 to 5 respectively. Again, work life balance was measured using 5 items designed by Valcour ( 2017); and the items were provided on Likert scale ranged from highly dissatisfied (1) to highly satisfied (5).

\subsection{Validity and Reliability}

The questionnaire used in this study are standard whose validity and reliability tested by the respective developers. However, the researcher made the internal consistency test through Cronbach Alpha to re-affirm the reliability of the questionnaire. The field's acceptable range of Cronbach alpha value is between 0.70 to 0.95 (Tavakol \& Dennick, 2011) and the result of the study is within the acceptable ranges of the field. 
Table 3.4: Reliability analysis

\begin{tabular}{|c|l|c|c|}
\hline No. & Description & No. of Items in the Scale & Cronbach Alpha \\
\hline 1 & Work Family Conflict (WFC) & 9 & .793 \\
\hline 2 & Family Work Conflict (FWC) & 9 & .881 \\
\hline 3 & Perceived organizational Support (POS) & 6 & .729 \\
\hline 4 & Perceived Social Support (PSS) & 8 & .821 \\
\hline 5 & Work life balance (WLB) & 5 & .864 \\
\hline
\end{tabular}

Source: Survey 2019

\subsection{Data Analysis}

The primary data collected through semi-structured questionnaires analyzed using Statistical Package for Social Science (SPSS Version 22). Descriptive statistics such as frequencies, percentages, means and standard deviations were analyzed. Besides, the statistical results of correlation and regression analysis were conducted in this study.

\section{Findings and Discussion}

A total of 114 questionnaires were distributed to the respondents for data collection and only $93(81.5 \%)$ were collected.

Table 4.1: Descriptive Statistics

\begin{tabular}{|c|c|c|c|c|c|}
\hline & $\mathbf{N}$ & Minimum & Maximum & Mean & Std. Deviation \\
\hline \multicolumn{6}{|l|}{ Independent Variables } \\
\hline Time Based Work-Family Conflict & 93 & 1 & 5 & 3.76 & .830 \\
\hline Strain Based Work -Family Conflict & 93 & 1 & 5 & 3.75 & .884 \\
\hline Behavior Based Work-Family Conflict & 93 & 1 & 5 & 3.03 & .839 \\
\hline Total Work-Family Conflict & 93 & 1 & 5 & 3.51 & .646 \\
\hline Time Based Family-Work Conflict & 93 & 1 & 5 & 2.99 & 1.026 \\
\hline Strain Based Family-Work Conflict & 93 & 1 & 5 & 2.78 & 1.138 \\
\hline Behavior Based Family-Work Conflict & 93 & 1 & 5 & 2.90 & .875 \\
\hline Total Family-Work Conflict & 93 & 1 & 5 & 2.89 & .874 \\
\hline Perceived Organizational Support & 93 & 1 & 5 & 3.64 & .507 \\
\hline Perceived Social Support & 93 & 1 & 5 & 4.02 & .598 \\
\hline \multicolumn{6}{|l|}{ Dependent Variable } \\
\hline Work Life Balance & 93 & 1 & 5 & 2.91 & .798 \\
\hline Valid N (List wise) & 93 & & & & \\
\hline
\end{tabular}

Source: Survey 2019

\subsection{Descriptive Statistics of the Variables}

According to Pihie (2009), a mean score less than or equivalent to 3.39 is low, a mean score that range from 3.40 to 3.79 is moderate and a score of more than or equal to 3.80 is high respectively on 5-point Likert scale.

Descriptively, the mean score of the participants' response about the level of their work to family or life conflict was $3.51(\mathrm{SD}=.646)$; and this indicates a moderate work to family conflict. Among the three dimensions of work to life conflict, behavior based work to family/life conflict exhibits low mean scare, $3.03(\mathrm{SD}=.839)$ compared to two other dimensions which both show moderate level of average scores, $3.76(\mathrm{SD}=.830)$ for time based and $3.75(\mathrm{SD}=.884)$ for strain based work to family conflict respectively. The implication is that church leaders of the EECMY experience reasonable work to family conflict.

Furthermore, the mean score of the respondents about the level of their family or life to work conflict was 2.89 ( $\mathrm{SD}=.878)$; and his signifies a low level of family to work conflict. All the elements of family/life to work conflict displayed low mean scores, time based conflict (Mean=2.99, SD=1.026), strain based conflict (Mean=2.78, SD=1.138), and behavior based conflict (Mean=2.90, $\mathrm{SD}=.875$ ) respectively. The standard deviation of the time based conflict and strain based conflict respectively were a little positively away from the average.

Among the elements of work-life conflict, time-based conflict shows highest mean score (2.99, SD=1.026), followed by behavior-based conflict $(2.90, \mathrm{SD}=0.875)$, and strain-based conflict has low average score than the rest with mean score of 2.78 and standard deviation of 1.138 . The result suggests that the roles in the family/life domain have minimal intrusion with work responsibilities of the church leaders of the EECMY.

Again, in comparing the mean scores of the work to family conflict with that of family to work conflict, the former has higher mean, 3.51( $\mathrm{SD}=.646)$ than the mean of the later, $2.89(\mathrm{SD}=.878)$. But, on the range, work to 
family conflict has moderate score while family to work conflict exhibits low result respectively. This implies that church leaders experience more work to family conflict than family to work conflict, which could be because church leaders give more time and attention to work than their non-work activities such as family and life. This inline with the study by Frone (2003) who after reviewed some literatures stated that "work-to-family conflict is reported to occur more frequently than family-to-work conflict. Thus, it appears that work has a more deleterious impact on life than life has on work." Darcy and McCarthy (2007) also notified that most of the time people experience conflict from work to family than family to work conflict; and Cinamon (2009) again attested that family sphere is more prone to penetration of work-related activities from work domain which causes work to life conflict.

Besides, the response of the participants about the degree of their perceived organizational support generated the mean score of $3.64(\mathrm{SD}=.507)$; and this shows moderate support from organization is perceived by the respondents. This result indicates that leaders of the EECMY perceived temperate amount of support from their organization.

Moreover, the mean score of the respondents' response about the perceived social support was 4.02 $(\mathrm{SD}=.599)$. This means that respondents perceived high social support. This result shows that church leaders perceived higher support from family, parents, friends, compared to the support they get form their organizations, which is moderate.

Finally, the participants' response about the extent of work life balance indicated the average score of 2.91 $(\mathrm{SD}=.798)$. This score discloses that respondents practice low level work life balance. The result suggests that the church leaders of the EECMY experience improper balance between their work and family/life related responsibilities. Many reasons such as lack of enough work life balance strategies, family-friendly policies, family-supportive culture/environment or inadequate utilization of such polices, carrying many work roles to home or family, personality of the managers/supervisors and so on could bring low work life balance.

\subsection{Correlation}

\section{Table 4.2: Correlation}

\begin{tabular}{|c|l|c|c|c|c|}
\hline \multicolumn{2}{|c|}{} & $\begin{array}{c}\text { Work-life } \\
\text { Conflict }\end{array}$ & $\begin{array}{c}\text { Life Work } \\
\text { Conflict }\end{array}$ & $\begin{array}{c}\text { Perceived } \\
\text { Organizational } \\
\text { Support }\end{array}$ & $\begin{array}{c}\text { Perceived } \\
\text { Social } \\
\text { Support }\end{array}$ \\
\hline \multirow{2}{*}{$\begin{array}{c}\text { Work-Life } \\
\text { Balance }\end{array}$} & Pearson Correlation & $-.418^{* *}$ & $-.275^{* *}$ & .117 & .054 \\
\cline { 2 - 6 } & Sig. (2-tailed) & .000 & .008 & .262 & .610 \\
\cline { 2 - 6 } & $\mathrm{N}$ & 93 & 92 & 93 & 93 \\
\cline { 2 - 6 } & $* *$ Correlation is significant at the 0.01 level (2-tailed). \\
\hline
\end{tabular}

Source: Survey 2019

Table 4.2 above shows that work to family/life conflict has negative relationship with work-life balance of the respondents $(\mathrm{r}=-.418, \mathrm{p}=.000)$, the significant level of 0.01 , and also a negative relationship between family/life to work conflict and work life balance $(\mathrm{r}=-.275, \mathrm{p}=.008)$. The results are in agreement with the pervious works of the researchers, for instance Lee and his associates (2014), Rincy and Panchanatham (2010), and Banu and Duraipandian (2014); hence, hypothesis 1 and 2 are supported.

Moreover, table 4.2 has indicated a non-significant relationship between perceived organizational support and work life balance $(\mathrm{r}=.262, \mathrm{p}>0.05)$; and also a non significant relationship between the perceived social support and work life balance $(\mathrm{r}=.610, \mathrm{p}>0.05)$; therefore, the hypothesis 3 and 4 are not supported.

Scholars have indicated such a non-significant relationship between perceived organizational support and work-life balance. Ahmad (1997) tried to study the relationship between social support and work family conflict found that support from friends and relatives and co-workers have no significant relationships with work family conflict. Moreover, Darcy and McCarthy (2013) studied the impact of parenting life cycle stage on work-family conflict identified that managerial support (part of organizational support) could not exhibit significant association with and avert the effect of work to family conflict on all the parental groups. Thus, managerial support cannot bring the intended effect in improving work-life balance if it failed to mitigate the impact of work to family conflict, which always perceived to have detrimental impact on work life balance. These authors in justifying their argument, claimed that "The company culture, and more specifically the views of managers and colleagues appear to present a barrier to the utilization of such [supports].

Additionally, Wong and his partners (2017) quoting a study by $\mathrm{Wu}$ and associates attested that supervisors support, which is one part of organizational support, plays very minor role in realizing work life balance of employees. Moreover, these authors also claimed that some scholars considered supervisors as major source of stressors for employees than providing necessary support to avert stress and promote work-life balance. Hence, this indicates that supervisor support contributes less in improving work-life balance of workers.

The non-significant relationship between perceived organizational support and perceived social support and 
work-life balance could be because of the differences in the cultural background of the respondents, the company or organizational culture (Cinamon 2009) and the nature of the job of the church leaders, the non-availability or irrelevance of the supports provided by the organization, and failure of employees to utilize and then recognize the available supports. McMinn and his associates (2005) stated that "It is striking to see how rarely clergy turn to relationships outside their families for support."; and this is because of the way pastors perceive themselves, especially being a model of Christian virtues and they are "boxed in" by parishioners' expectations of ways pastors should behave which can have an isolating effect. Again, Morris and Blanton(1995) identified 21 items categorized into four support services, and concluded that "majority of clergy and their wives perceived that their sponsoring denominations were not making available those services that they perceived were important, and denominations may not be providing support services that enhance the quality of life for the entire clergy family system."

\subsection{Regression Analysis}

Table 4.3 (1): Model Summary

\begin{tabular}{|c|c|c|c|c|}
\hline Model & $\mathrm{R}$ & $\mathrm{R}$ Square & Adjusted R Square & $\begin{array}{c}\text { Std. Error of the } \\
\text { Estimate }\end{array}$ \\
\hline 1 & $.425^{\mathrm{a}}$ & .181 & .143 & 3.663 \\
\hline
\end{tabular}

a. Predictors: (Constant), WLC, LWC, POS, PSS

Table 4.3(2)

ANOVA

\begin{tabular}{|c|c|c|c|c|c|}
\hline Model & Sum of Squares & df & $\begin{array}{l}\text { Mean } \\
\text { Square }\end{array}$ & $F$ & Sig. \\
\hline $\begin{array}{c}\text { Regression } \\
\text { Residual } \\
\text { Total }\end{array}$ & $\begin{array}{l}257.405 \\
1167.584 \\
1424.989\end{array}$ & $\begin{array}{c}4 \\
87 \\
91\end{array}$ & $\begin{array}{l}64.351 \\
13.421\end{array}$ & 4.795 & $.002^{\mathrm{b}}$ \\
\hline
\end{tabular}

a. Dependent Variable: WLB

b. Predictors: (Constant), WLC, LWC, POS, and PSS

Table 4.3(3):

\section{Coefficients}

\begin{tabular}{|c|c|c|c|c|c|}
\hline \multirow[b]{2}{*}{ Model } & \multicolumn{2}{|c|}{$\begin{array}{c}\text { Unstandardized } \\
\text { Coefficients } \\
\end{array}$} & \multirow{2}{*}{$\begin{array}{c}\text { Standardized } \\
\text { Coefficients }\end{array}$} & \multirow[b]{2}{*}{ t } & \multirow[b]{2}{*}{ Sig. } \\
\hline & B & Std. Error & & & \\
\hline 1 (Constant) & 19.381 & 4.459 & & 4.347 & .000 \\
\hline Work Life Conflict & -.242 & .079 & -.351 & -3.057 & .003 \\
\hline Life Work Conflict & -.053 & .057 & -.104 & -.922 & .359 \\
\hline Perceived Organizational Support & .062 & .130 & .047 & .475 & .636 \\
\hline Perceived Social Support & .089 & .081 & .108 & 1.099 & .275 \\
\hline
\end{tabular}

a. Dependent Variable: WLB

Source: Survey 2019

Table 4.3(1) above indicates that work to family/life conflict (WLC), life to work conflict (LWC), perceived organizational support(POS) and perceived social support (PSS) predict the work life balance (WLB) of the church leaders, $\mathrm{R}=.425$. The value of $\mathrm{R}^{2}=0.181$ implies that the independent variables explain only $18.1 \%$ of the variability of the work-life balance. The remaining portion is explained by the other variables.

Table 4.3(2) shows good fitness of regression analysis for the data, $\mathrm{F}(4,91)=4.795, \mathrm{P}<.001$ and this means that the regression analysis fits well for these data.

Table 4.3(3) indicates that among the independent variables, work to life conflict has negative and strong standardized beta coefficient and $\mathrm{p}$ value $(\beta=-0.351, \mathrm{p}=0.003)$ respectively. Compared to other independent variables, work to life conflict highly predicts work-life balance. This shows work-life conflict has strong and negative effect on work-life balance of the church leaders at a significant level of $0.01(1 \%)$; thus, hypothesis 1 is affirmed.

The result agrees with the previous studies such as Tasdelen-Karckay and Bakalim (2017), and Chawla and Sonshi (2011). The finding shows that church leaders of the EECMY carried some work related roles, behaviors and so forth to homes which consume and minimize their time, energy and participation in home related affairs. High work to family conflict leads to improper work life balance of the church leaders which can eventually leads to low satisfaction, low performance, physical and mental health related problems, stress, marriage and family instability, and so on. 
Table 4.3(3) also reveals that life to work conflict, perceived organizational support, and perceived social support do not significantly affect work life balance. Hence, the result did not support hypothesis 2, 3 and 4 respectively. Accordingly, Namayaneh and his colleagues (2010) examined the effects of workplace supports from supervisors and co-workers and social support from husband, family members and relatives on work-family conflict found that co-workers support has non-significant effect on work-family conflict(work-life balance) due to cultural context. Thus, this indicates that support from co-workers could not be relevant in lessening work life conflict and in turn improve work life balance.

Likewise, Kirrane and Buckley (2004) studied the variance influence of the supports from work colleagues, supervisors, spouse/partner, friends, and relatives on the balance between their work and family life roles and indicated that social support mostly from spouse/partner, friends, relatives, co-workers, workplace supervisors have no significant impact on work life conflict, that is, they raised work life conflict, which in turn lowered work life balance of the workers. Besides, Abendroth and Dulk (2011) while trying to study the relevance of support (from state, workplace and family) in improving employees satisfaction with work life balance concluded that "not all types of supports appear to have positive impact on work life balance", hence, the importance of such supports must be seen, utilized and executed with due care.

The non-significant effect of life to work conflict, perceived organizational support and perceived social support on work life balance could be due to organizational culture and other factors. According to Darcy and McCarthy (2007), "Strongly held informal cultural values can have the effect of negating any formal family friendly policies [one aspect of organizational support] which may be in place within an organization."

\section{Summary, Conclusion and Recommendations 5.1 Summary}

The descriptive statistics indicated that leaders of the EECMY are experiencing moderate work to life conflict. This is also exhibited by two elements of the work to family conflict (time and strain based conflicts) despite the fact that behavior-based conflict shows low level compared to others. Furthermore, the descriptive statistics explained family to work conflict and its components (time, strain and behavior conflict). The result indicated that the degree of family to work conflict experienced by the church leaders is low, and this is also shown by its elements. Again, the level of church leaders' perceptions of support from the organizations, as per the descriptive statistics is at moderate degree. On the other hand, as indicated by the result of descriptive statistics, church leaders perceived high level of support from family, friends and significant others. Additionally, the descriptive revealed that church leaders of the EECMY practiced low level of work life balance.

Moreover, the result of the analysis showed that work to family/life conflict has significantly inverse correlation and effect on work life balance of the church leaders. Again, the finding indicated that family/life to work conflict negatively related to but has non-significant effect on work life balance. Besides, is was revealed that perceived organizational support has no significant association with and effect on work life balance. Likewise, church leaders' perception of social support exhibited a non-significant relationship with and effect on perceived work life balance. The reasons behind the non-significant relationship and effect of perceived organizational support and perceived social support could be differences in the cultural background of the church leaders, the company culture and job nature, the availability and relevance of support services, the recognition and utilization of such supports by the employees and so forth.

Generally, the study affirmed that church leaders of the EECMY experienced low work life balance which was mainly predicted by work to life/family conflict. But work to family conflict has most effect on work life balance of the leaders compared to family to work conflict.

\subsection{Conclusion}

To conclude, first, the church leaders are possessed with work-related roles while at homes which make them have very little or no time and energy to discharge significantly other non-work responsibilities; and they also carry family roles to workplace though the magnitude is less when compared to how work roles affect their homes. Secondly, church leaders perceived moderate support from its organization but such supports could not be enough or relevant to enhance balanced work and life obligations. Hence, this could be due to lack of human resource policies, strategies or family-friendly polices, initiatives, and adequate family supportive environment, inadequate utilization of available polices and initiatives, and so forth. Thirdly, the church leaders perceived high social supports from their families, friends, relatives and significant others, however, such supports could not significantly be relevant in improving their work life balance.

Generally, the church leaders are experiencing imbalanced work and life responsibilities mainly due to work to life conflict, lack relevant and properly utilized organizational and social supports. Hence, low work life balance, may lead to low motivation and performance, stressful environments and high emotional exhaustion, low life satisfaction, poor appetite and fatigue, physical and mental health problems and so on. 


\subsection{Recommendations}

In order for its leaders to have improved work life balance, the church (EECMY) must introduce and invest in different work-life balance strategies, policies and initiatives; initiate family supportive working environment and culture; provide awareness about the importance and consequence of work life balance, time and stress management, family and marriage management and so forth; formulate and introduce health and physical exercise related polices; adequately implement and encourage its leaders and employees to utilize the already available polices like leave arrangements; organize and provide necessary resources including financial supports for times of family retreats and vacations.

Moreover, to have balanced work and life roles leaders and church employees should advocate for familyfriendly benefits and supportive culture in the organization, utilize such benefits, effectively manage and allocate their times, have family and friends who can provide supports in the time of need(s).

\section{Bibliography}

Abendroth, A.-K., \& Dulk, L. Den. (2011). Support for the work-life balance in Europe: the impact of state, workplace and family support on work-life balance satisfaction. Work, Employment and Society, 25(2), 234-256.

Ahmad, A. (1997). Work-Family Conflict and Social Support: A Study of Female Secretaries in Malaysia. Pertanika Journal of Social Science and Humanities, 5(2), 93-101.

AlHazemi, A. A., \& Ali, W. (2016). The Notion of Work Life Balance, Determining Factors, Antecedents and Consequences: A Comprehensive Literature Survey. International Journal of Academic Research and Reflection, 4(4), 74-85.

Banu, A. R., \& Duraipandian, K. (2014). Development of an Instrument to Measure Work Life Balance of It Professionals in Chennai. International Journal of Management, 5(11), 21-33.

Biddle, B. J. (1986). Recent Developments in Role Theory. Annual Reviews Inc., 12, 67-92.

Carlson, D. S., Kacmar, K. M., \& Williams, L. J. (2000). Construction and Initial Validation of a Multidimensional Measure of Work-Family Conflict. Journal of Vocational Behavior, 56, 249-276.

Chawla, D., \& Sondhi, N. (2011). Assessing Work-Life Balance Among Indian Women Professionals. The Indian Journal of Industrial Rela, 47(2), 341-352.

Cinamon, R. G. (2009). Role Salience, Social Support, and Work-Family Conflict Among Jewish and Arab Female Teachers in Israel. Journal of Career Development, 36(2), 139-158.

Clark, S. C. (2000). Work/Family Border Theory: A New Theory of Work/Family Balance. Sage Publications/Human Relations, 53(6), 747-770.

Constitution and Bylaws of the Ethioipan Evangelical Church Mekane Yesus. (2004). The EECMY.

Darcy, C., \& McCarthy, A. (2007). Work-family conflict: An exploration of the differential effects of a dependent child's age on working parents. Journal of European Industrial Training/Emerald Group Publishing Limited, 31(7), 530-549.

De Cieri, H., Holmes, B., Abbott, J., \& Pettit, T. (2005). Achievements and challenges for work/life balance strategies in Australian organizations. Taylor \& Francis Group Ltd, 16(1), 90-103.

Eisenberger, R., Huntington, R., Hutchison, S., \& Sowa, D. (1986). Perceived Organizational Support. Journal of Applied Psychology, 7(3), 500-507.

Ethical Imperatives of Work/Life Balance. (2012). In International Handbooks of Quality-of-Life. Work and Quality of Life: Ethical Practices in Organizations (p. 507). Dordrecht: Springer Science+Business Media.

Ethiopian Peoples' Federal Democratic Republic of ETh. Constitution of the Federal Democratic Republic of Ethiopia. , (1995).

Family Issues and Work-Life Balance. (n.d.). European Agency for Safety and Health at Work, 1-8.

Ferguson, M., Carlson, D., Zivnuska, S., \& Whitten, D. (2012). Support at work and home: The path to satisfaction through balanc. Journal of Vocational Behavior, 80, 299-307.

Frone, M. R. (2003). Work-Family Balance. In Handbook of Occupational Pyschology (pp. 143-162). Washington DC.

Greenhaus, J. H., \& Beutell, N. J. (1985). Sources of Conflict between Work and Family Roles. The Academy of Management Review, 10(1), 76-88.

Guest, D. E. (2002). Perspectives on the Study of Work-life Balance. Social Science Information and Sage Publications, 41(2), 255-279.

Hill, E. J., Hawkins, A. J., Ferris, M., \& Weitzman, M. (2001). Finding an extra day a week: the positive influence of perceived job flexibility on work and family life balance. Family Relations: Interdisciplinary Journal of Applied Family Studies, 50, 49-58.

Hogarth, T., \& Bosworth, D. (2009). Future horizons for work-life balance. Institute for Employment Research, University of Warwick, 1-10.

Kaya, D., Akgemci, T., \& Çelik, A. (2012). A Research Levels of Perceived Social Support on the Responsible 
Persons of the Hospital Units. Ç. Ü. Sosyal Bilimler Enstitüsü Dergisi, 21(3), 357-370.

Kebriaei, A., Abedizadeh, F., \& Sharifian, T. (2016). Study on the Conflicts between Work and Family at the Kashan University of Medical Sciences, Iran. International Letters of Social and Humanistic Sciences, 74, $48-53$.

Kirrane, M., \& Buckley, F. (2004). The influence of support relationships on work-family conflict: differentiating emotional from instrumental support. Equal Opportunities International, 23(1/2), 78-96.

Kumar, G. V., \& Janakiram, B. (2017). Theories of Work Life Balance -a Conceptual Review. Associated Asia Research Foundation (AARF), 4(9), 184-192.

Lee, N., Zvonkovic, A. M., \& Crawford, D. W. (2014). The Impact of Work-Family Conflict and Facilitation on Women's Perceptions of Role Balance. Journal of Family Issues, 35(9), 1252-1274.

Lockwood, N. R. (2003). Work/Life Balance Challenges and Solutions. Society For Human Resource Management(SHRM), 1-10.

Malik, M. I., Saif, M. I., Gomez, S. F., Khan, N., \& Hussain, S. (2010). Balancing work and family through social support among working women in Pakistan. African Journal of Business Management, 4(13), 28642870 .

Maxwell, J. A. (2013). Qualitative Research Design: An Interactive Approach (3rd ed). Thousand Oaks, Calif: SAGE Publications.

May, M., \& Reynolds, J. (2017). Religious Affiliation and Work-Family Conflict Among Women and Men. Journal of Family Issues and SAGE, 1-30.

McCarthy, A., Cleveland, J. N., Hunter, S., Darcy, C., \& Grady, G. (2013). Employee work-life balance outcomes in Ireland: a multilevel investigation of supervisory support and perceived organizational support. The International Journal of Human Resource Management, 24(6), 1257-1276.

McMinn, M. R., Lish, R. A., Trice, P. D., Root, A. M., \& Gilbert, N. B. (2005). Care For Pastors: Learning From Clergy and Their Spouses. Faculty Publications - Grad School of Clinical Psychology, 152, 1-21.

Meenakshi, S. P., Subrahmanyam C. V., V., \& Ravichandran, K. (2013). The Importance of Work-Life-Balance. IOSR Journal of Business and Management (IOSR-JBM), 14(3), 31-35.

Morris, M. L., \& Blanton, P. W. (1995). The availability and importance of Denominational Support Services as perceived by Clergy Husbands and their wives. Pastoral Psychology, 44(1), 29-44.

Muna, F. A., \& Mansour, N. (2009). Balancing work and personal life: the leader as acrobat. Emerald Group Publishing Limited, 28(2), 121-133.

Namayandeh, H., Yaacob, S. N., \& Juhari, R. (2010). The Influences of work support and family support on Work- Family Conflict (W-FC) Among Married Female Nurses in Shiraz-Iran. Journal of American Science, 6(12), 534-540.

Onyebuchukwu, I. J., Emerenwa, A. B. C., Ogwa, F., Evbuoma, K., \& Igbokwe, D. O. (2015). Perceived Social Support, Perceived Stress as Correlates of Stress Symptomatology among University Students. Covenant International Journal of Psychology (CIJP). Maiden Edition., 1(1), 27-34.

Pension Contributors' statistics for 2018. (2018). The EECMY, Pension, Insurance and Investment Commision, Pension section.

Pichler, F. (2009). Determinants of Work-Life Balance: Shortcomings in the Contemporary Measurement of WLB in Large-Scale Survey. Springer (Social Indicators Research), 92(3), 449-469.

Pihie, Z. A. L. (2009). Precipitation variability on the massif Forest of Mahouna (North Eastern-Algeria) from 1986 to 2010. International Journal of Management Sciences and Business Research, 5(3).

Pradhan, G. (2016). Conceptualising work-life balance. Bangalore: Institute for Social and Economic Change.

Rao, T. S. S., \& Indla, V. (2010). Work, family or personal life: Why not all three? Indian Journal of Psychiatry, 54(2), 295-297.

Rincy, V. M., \& Panchanatham, N. (2010). Development of a Psychometric Instrument to Measure Work Life Balanc. Continental Journal of Social Sciences, 3, 50-58.

Russo, M., Shteigman, A., \& Carmeli, A. (2015). Workplace and family support and work-life balance: Implications for individual psychological availability and energy at work. The Journal of Positive Psychology, 1-16.

Saleem, A., \& Abbasi, A. S. (2015). Impact of Life and Job Domain Characteristics on Work Life Balance of Textile Employees in Pakistan. Science International(Sci.Int.(Lahore)), 27(3), 2409-2416.

Sangarry, S. B., \& Srinivasan, V. (2016). Work/Life Balance - Challenges and Solutions in Present Scenario. International Conference on “Innovative Management Practices, " 1(1), 6-12.

Singh, S. (2014). Measuring Work-life Balance in India. International Journal of Advance Research in Computer Science and Management Studies, 2(5), 35-45.

Tasdelen-Karckay, A., \& Bakalim, O. (2017). The mediating effect of work-life balance on the relationship between work- family conflict and life satisfaction. Australian Journal of Career Development, 26(1), 3-13.

Tavakol, M., \& Dennick, R. (2011). Making sense of Cronbach's alpha. International Journal of Medical 
Education., 2, 53-55.

Terfassa, D. O. (2017). Serving the Whole Person: The Case of the Ethiopian Evangelical Church Mekane Yesus(EECMY). Norwegian Journal of Missiology, 4, 35-44.

Thakur, A., \& Kumar, N. (2015). The Effect of Perceived Organizational Support, Role Related Aspects and Work Involvement on Work-Life Balance: Self Efficacy as a Moderator. International Journal of Scientific and Research Publications, 5(1), 1-8.

The Case for Work/Life Balance: Closing the Gap Between Policy and Practice 20:20 Series. (2005). Hudson Resource Development, 20(20), 2-36.

The Ethiopian Evangelical Church Mekane Yess Statistics for 2017. (2018). The EECMY: Yemisrach Dimts Communication Services (Agenda 2018-2019, Addis Ababa).

Valcour, M. (2017). Work-Based Resources as Moderators of the Relationship Between Work Hours and Satisfaction With Work-Family Balance. Journal of Applied Psychology, 92(6), 1-12.

Vinokur, A. D., \& Van Ryn, M. (1993). Social Support and Undermining in Close Relationships: Their Independent Effects on the Mental Health of Unemployed Persons. Journal of Personality and Social Psychology, 65(2), 350-359. https://doi.org/10.1037/0022-3514.65.2.350

Viswanathan, K., \& Jeyakumaran, Dr. (2013). Instrument Development for Studying Work Life Balance Programs in Information Technology Firms. IOSR Journal of Business and Management, 11(4), 47-53.

Wong, P.-Y., Bandar, N. F. A., \& Saili, J. (2017). Workplace Factors and Work-Life Balance Among Employees in Selected Services Sector. International Journal of Business and Society, 18(4), 677-684.

Work-Family Balance:A Review and Extension of the Literature. (2011). In Handbook of Occupational Health Psychology (2nd ed., pp. 165-183).

Work-life balance. (2015). In Managing Diversity and inclusion: An International Perspective (pp. 291-314).

Yahya, F., \& Yap, J. Y. Y. (2014). The Work Social Support and Work -Life Balance in Hotel Industry: A Relationship Study. Malaysian Journal of Youth Studies, 11, 27-40.

Zhang, M., Foley, S., Li, H., \& Zhu, J. (2018). Social support, work-family balance and satisfaction among Chinese middle- and upper level managers: testing cross-domain and within domain effects. The International Journal of Human Resource Management, 1-23. 